\title{
Epidemiologic characteristics of orthopedic surgical site infections and under-reporting estimation of registries using capture- recapture analysis
}

Niloufar Taherpour ${ }^{1}$ (D), Yadollah Mehrabi ${ }^{1}$ (D), Arash Seifi ${ }^{2}$ (D) Babak Eshrati ${ }^{3}$ (D) and Seyed Saeed Hashemi Nazari ${ }^{4,5^{*}}$ (D)

\begin{abstract}
Background: Surgical Site Infections (SSIs) are among the leading causes of the postoperative complications. This study aimed at investigating the epidemiologic characteristics of orthopedic SSIs and estimating the under-reporting of registries using the capture-recapture method.

Methods: This study, which was a registry-based, cross-sectional one, was conducted in six educational hospitals in Tehran during a one-year period, from March, 2017 to March, 2018. The data were collected from two hospital registries (National Nosocomial Infection Surveillance System (NNIS) and Health Information Management database $(\mathrm{HIM})$ ). First, all orthopedic SSIs registered in these sources were used to perform capture-recapture $(N=503)$. Second, 202 samples were randomly selected to assess patients`characteristics.

Results: Totally, $76.24 \%$ of SSIs were detected post-discharge. Staphylococcus aureus (11.38\%) was the most frequently detected bacterium in orthopedic SSIs. The median time between the detection of a SSI and the discharge was 17 days. The results of a study done on 503 SSIs showed that the coverage of NNIS and HIM was 59.95 and 65.17\%, respectively. After capture-recapture estimation, it was found that about 221 of orthopedic SSIs were not detected by two sources among six hospitals and the real number of SSIs were estimated to be $623 \pm 36.58(95 \% \mathrm{Cl}, 552-695)$ and under-reporting percentage was 63.32\%.

Conclusion: To recognize the trends of SSIs mortality and morbidity in national level, it is significant to have access to a registry with minimum underestimated data. Therefore, according to the weak coverage of NNIS and HIM among Iranian hospitals, a plan for promoting the national Infection Prevention and Control (IPC) programs and providing updated protocols is recommended.
\end{abstract}

Keywords: Surgical site infection, Orthopedic surgery, Surveillance system, Capture-recapture

\footnotetext{
*Correspondence: saeedh_1999@sbmu.ac.ir

${ }^{4}$ Prevention of Cardiovascular Disease Research Center, Department of Epidemiology, School of Public Health and Safety, Shahid Beheshti University of Medical Sciences, Tehran, Iran

${ }^{5}$ School of Public Health and Safety, Shahid Beheshti University of Medical Sciences, Daneshjoo Blvd, Evin Ave, Tehran Postal code: 198353-5511, Iran Full list of author information is available at the end of the article
}

(c) The Author(s). 2021 Open Access This article is licensed under a Creative Commons Attribution 4.0 International License, which permits use, sharing, adaptation, distribution and reproduction in any medium or format, as long as you give appropriate credit to the original author(s) and the source, provide a link to the Creative Commons licence, and indicate if changes were made. The images or other third party material in this article are included in the article's Creative Commons licence, unless indicated otherwise in a credit line to the material. If material is not included in the article's Creative Commons licence and your intended use is not permitted by statutory regulation or exceeds the permitted use, you will need to obtain permission directly from the copyright holder. To view a copy of this licence, visit http://creativecommons.org/licenses/by/4.0/ The Creative Commons Public Domain Dedication waiver (http://creativecommons.org/publicdomain/zero/1.0/) applies to the data made available in this article, unless otherwise stated in a credit line to the data. 


\section{Background}

Surgical Site Infection (SSI) is one of the most common surgical-related problems in the world, especially in developing countries [1]. SSI is a kind of Nosocomial Infections (NIs) - also called Health care-associated Infections (HAIs) that occur within 30 days of the procedure or in a one-year period if mechanical or prosthetic material is implanted at surgery [2]. SSI is responsible for mortality, long hospitalization period, and a high economic burden [3]. According to the past reports, the incidence rate of SSI is globally about 10-20\% [4] and is the most frequent type of HAIs in low and middle income countries [5]. The most commonly reported microorganism is gram-negative Escherichia-coli, accounting for $6.7-50 \%$ of incidence, and the second one is gram-positive Staphylococcus aureus, causing SSI in procedures [6]. According to the European Center for Disease prevention and Control (ECDC), the percentage of SSI varies from 0.5 to $9.0 \%$, depending on the type of procedure [7]. As stated by the World Health Organization (WHO), due to the limited and low quality of data in low and middle-income countries, the incidence and prevalence of SSIs are underestimated. Considering the reports of different countries, WHO estimated that the prevalence of HAI varies between 5.7 and 19.1\% in low- and middle-income countries [8]. In Eastern Mediterranean regions, the overall prevalence of SSI was reported to be about $7.9 \%$ in 2019 [9]. The overall prevalence of HAI in Iran, as a middle-upper-income country, was about $4.5 \%$ in 2017 , where bloodstream infections, surgical site infections, and pneumonia were the most common types of HAIs in Iran, respectively [4].

Due to the nature of orthopedic surgeries and special patients under this procedure with variety of conditions and disorders (older patients especially in arthroplasty surgeries, underlying diseases and penetrating trauma) the risk of surgical site infection is higher compared to other procedures. The incidence of orthopedic SSIs in Iran was $8.8 \%$ in 2018; This type of infection has been responsible for long hospitalization period and bad prognosis $[10,11]$.

In Iran, there are two hospital information sources for registering HAIs. One of these information sources is Health Information Management (HIM) that plays a role in maintaining and collecting the medical records. In this unit, all medical and health information of patients is registered based on ICD-10 and ICD-9-CM coding system [12]. The second source is the National Nosocomial Infections Surveillance system (NNIS), a computerbased software, which was launched in 2011. In this Iranian surveillance system, the information of HAIs such as demographic characteristics of patients, vital status of them, Length of stay (LOS) or the duration of hospitalization, type of HAIs, device utility days, laboratory information by hospitals and wards are recorded
[13]. Therefore, since these two sources of information do not depend on one another, some HAIs may not be detected by the NNIS. Also, owing to the lack of up-todate instructions and the occurrence of human errors, the diagnosed HAIs may not be reported completely, which results in underestimation.

Thus, to realize the real distribution and trends of diseases in order for controlling and preventing its outcomes in the country, complete data with minimum underestimation is required. This study was conducted aiming at the estimation of the number of orthopedic SSIs from 2017 to 2018 using the capture-recapture method. At the second stage, the existing problems in NNIS among hospitals under study in Iran were reported.

\section{Methods}

This registry-based, cross-sectional study was conducted in six educational hospitals in Tehran from March, 2017 to March, 2018. First, six hospitals (over 250 beds) were randomly selected. After that, data were collected from two sources in hospitals. One of them is the information of patients infected in orthopedic surgeries from 21 March, 2017 to 21 March, 2018 - orthopedic SSIs were based on the health information management (HIM) reporting. The second one was the orthopedic SSIs which were based on National Nosocomial Infections Surveillance system (NNIS) registries in each six mentioned hospitals. Overall, we collected 262 and 241 identical codes of SSIs from HIM and NNIS, respectively from 2017 to 2018 ( $N=503$, after the exclusion of duplicates) Fig. 1. Five hundred-three SSIs were used for estimating the orthopedic SSIs population size using two- sources capture-recapture method. After that, from 503 identical codes, 202 medical records of orthopedic SSIs were randomly selected in order for monitoring the orthopedic SSI patients` characteristics.

\section{Two-source capture-recapture}

In ecologic and epidemiologic studies, capture-recapture sampling is a method used to estimate the completeness of ascertainment of disease registers and estimate the unknown size of a population [14]. We used a less biased alternative estimator of population size which is given by the Chapman estimator $[15,16]$. Also, categorical data (as frequencies and percentages) and quantitative data (median and interquartile range (IQR)) were calculated. To describe and compare subjects, T-test, Mann-Whitney and Chi-square $\left(\chi^{2}\right)$ tests at significant level of $<0.05$ were used. Data analysis was carried out using STATA.14 software. 


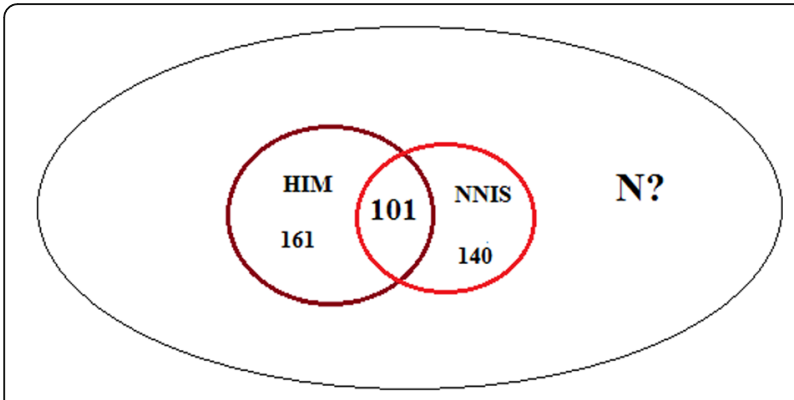

Fig. 1 Distribution of orthopedic SSIs among six educational hospitals in Tehran based on two data sources

\section{Results}

The results of studying 503 SSIs in six educational hospitals during the 2017-2018 period showed that the coverage percentages based on existing data in NNIS and HIM were 59.95 and $65.17 \%$, respectively (Table 1 ).

According to the results obtained from capturerecapture estimation, about 221 of SSIs were not detected by two sources in six hospitals and the real number of SSIs were estimated to be $623 \pm 36.58$ (95\% CI, 552-695). Furthermore, the completeness percentages of HIM and NNIS based on the capture-recapture method were 42.05 and $38.68 \%$, respectively and under-reporting was $63.32 \%$. This indicates the completeness of SSI registries was low, and about half of the cases were missed among the respective six hospitals in Tehran from 2017 to 2018.

In Table 2, among 202 orthopedic SSIs in the six respective educational hospitals, 148 (73.26\%) were males and $54(26.73 \%)$ were females. The median age of orthopedic SSI cases was 44 (32-62); 48 (23.76\%) SSIs were identified pre-discharge and 154 (76.24\%) of them were detected post-discharge. Overall, 92 (45.55\%) SSIs occurred during Open Reduction and Internal Fixation (ORIF), 80 (39.60\%) in other orthopedic surgeries, 19 $(9.40 \%)$ in Total Knee Arthroplasty (TKA), and 11(5.45\%) Total Hip Arthroplasty (THA). Staphylococcus aureus (11.38\%) and Klebsiella (10.89\%) were the most frequent bacteria in orthopedic SSIs. Furthermore, 5 (2.47\%) cases died due to orthopedic SSIs. A statistically significant association was observed between the type of microorganism $(P=0.001)$ and time between surgery to infection $(P<0.001)$ with occurrence of SSIs (post or pre discharge).

The median length of hospitalization due to surgery before infection occurrence was 11 (7-19) days. After operation, SSIs led to longer hospitalization with median of 17 (8-29) days. Also, the median length of surgery to infection occurrence was 27.5 days, which has been longer among post discharge SSIs $(36.5$ days) $(P<0.001)$ (Table 2).

According to the Table 3, 110 (54.46\%) orthopedic SSIs were totally detected within 30 days after the procedure. Furthermore, $17.82 \%$ of them were identified within 90 days to one year after the procedure. The details of SSIs characteristics are listed in Table 3. (Table 3).

\section{Discussion}

In the present study, the median age of SSIs was about 44 and most of them were males (73.26\%). About $2.47 \%$ of cases died due to orthopedic surgical site infection. These results are in line with other literatures in which SSI was more among males and middle-aged patients with fatality rate of $2-3 \%$. However, Al-Mulhim, et al. found that SSI was more common in younger patients with an average age of 38 in Saudi Arabia [17, 18].

Surgical site infection may lead to many complications, among which one is prolonged hospitalization due to infection. In this study, the median days of hospitalization due to orthopedic surgery was 17 days while the median length of hospitalization due to SSI was 11 days. This finding is similar to other prior studies that reported the mean of hospitalization days due to SSI; it varied from 4 to 32 days and the average length of increased hospitalization due to orthopedic SSIs was 19.8 days while the average length of stay for patients with no post-surgical infection was lower at 9.1 days [19-21]. Thus, SSI can increase the economic and psychological

Table 1 Results of the number of SSIs reported by NNIS compared to HIM among six educational hospitals under study in Tehran from March 2017 to March 2018

\begin{tabular}{|c|c|c|c|c|c|c|}
\hline Hospital code & $\begin{array}{l}\text { (a) HIM reported } \\
\text { cases }(n)\end{array}$ & $\begin{array}{l}\text { (b) NNIS reported } \\
\text { cases }(n)\end{array}$ & $\begin{array}{l}\text { (c) Common cases } \\
\text { between two } \\
\text { registries } n(\mathrm{c} / \mathrm{d} \%)\end{array}$ & $\begin{array}{l}\text { (d) Total number of } \\
\text { cases }(n)(a+b-c)\end{array}$ & $\begin{array}{l}\text { (e) Coverage of } \\
\text { NNIS (b/d \%) }\end{array}$ & $\begin{array}{l}\text { (F) Coverage of } \\
\text { HIM (a/d \%) }\end{array}$ \\
\hline Hospital 1 & 24 & 28 & $6(13.04)$ & 46 & 60.86 & 52.17 \\
\hline Hospital 2 & 6 & 6 & $0(0)$ & 12 & 50 & 50 \\
\hline Hospital 3 & 60 & 45 & $14(15.38)$ & 91 & 49.45 & 65.93 \\
\hline Hospital 4 & 42 & 6 & $2(4.34)$ & 46 & 13.04 & 91.30 \\
\hline Hospital 5 & 75 & 66 & $34(31.77)$ & 107 & 61.68 & 70.09 \\
\hline Hospital 6 & 55 & 90 & $45(45)$ & 100 & 90 & 55 \\
\hline Total & 262 & 241 & $101(25.12)$ & 402 & 59.95 & 65.17 \\
\hline
\end{tabular}


Table 2 Characteristics of SSIs in orthopedic surgery in six educational hospitals under study in Tehran from March 2017 to March 2018

\begin{tabular}{|c|c|c|c|c|}
\hline Variable & Post-discharge infection & Pre-discharge infection & Total & P_value \\
\hline Sex & & & & 0.152 \\
\hline Female & 45 (83.33) & $9(16.67)$ & 54 & \\
\hline Male & $109(73.65)$ & $39(26.35)$ & 148 & \\
\hline Vital status & & & & 0.388 \\
\hline live & $151(76.65)$ & $46(23.35)$ & 197 & \\
\hline Dead & $3(60.0)$ & $2(40.0)$ & 5 & \\
\hline Type of procedure & & & & 0.218 \\
\hline ORIF & $73(79.35)$ & $19(20.56)$ & 92 & \\
\hline TKA & $16(84.21)$ & $3(15.79)$ & 19 & \\
\hline THA & $9(81.82)$ & $2(18.18)$ & 11 & \\
\hline Other orthopedic surgeries & $56(70.0)$ & $24(30.0)$ & 80 & \\
\hline Bacteriology test & & & & $0.001^{*}$ \\
\hline E. coli & $6(75.0)$ & $2(25.0)$ & 8 & \\
\hline Entrobacter & $6(37.50)$ & $10(62.50)$ & 16 & \\
\hline Klebsiella & $12(54.55)$ & $10(45.45)$ & 22 & \\
\hline Pseudomonas aeruginosa & $6(85.71)$ & $1(14.29)$ & 7 & \\
\hline Staph aureous & $18(78.26)$ & $5(21.74)$ & 23 & \\
\hline Staph epidermis & $7(87.50)$ & $1(12.50)$ & 8 & \\
\hline Acinetobacter & $3(60.0)$ & $2(40)$ & 5 & \\
\hline Others $^{1}$ & $9(90.0)$ & $1(10.0)$ & 10 & \\
\hline Unknown & 87 (76.24) & $16(15.53)$ & 103 & \\
\hline Age (years) & $46(33.75-62.25)$ & $38.5(28-55.75)$ & $44(32-62)$ & 0.076 \\
\hline Time between surgery to infection (days) & $36.5(20.5-85.5)$ & $9(5.25-16)$ & $27.5(14-60)$ & $<0.001^{*}$ \\
\hline Length of hospitalization due to orthopedic surgery (days) ${ }^{2}$ & $10(6-17.25)$ & $13(8-23)$ & $11(7-19)$ & 0.052 \\
\hline Duration of hospitalization due to infection (days) ${ }^{3}$ & $17(8-28)$ & $17(7.25-30)$ & $17(18-29)$ & 0.685 \\
\hline Total & $154(76.24)$ & $48(23.76)$ & $202(100)$ & - \\
\hline
\end{tabular}

Data are $n$ (\%) or median (Q1-Q3).

${ }^{1}$ Such as Cocci, Proteous, Candida, Streptococ viridans and Entrococus Faecium

${ }^{2}$ Time between admission to discharge among the post-discharge infection group and duration between admission to detection of SSI among the pre-discharge infection cases

${ }^{3}$ The duration between detection of SSI to discharge

Table 3 Relative frequency of infection occurrence in different intervals after orthopedic surgery from March 2017 to March 2018

\begin{tabular}{|c|c|c|c|c|c|}
\hline Type of procedure (ICD9_CM) & $\leq 30$ (days) $n(\%)$ & $31-60$ days $n(\%)$ & $61-90$ days $n(\%)$ & $>90$ days $n(\%)$ & Total \\
\hline ORIF $^{1}$ & $48(52.17)$ & $20(21.74)$ & $6(6.52)$ & $18(19.57)$ & 92 \\
\hline TKA $^{2}$ & $13(68.42)$ & $3(15.79)$ & $1(5.26)$ & $2(10.53)$ & 19 \\
\hline THA $^{3}$ & $6(54.55)$ & $2(18.18)$ & 2 (18.18) & $1(9.09)$ & 11 \\
\hline Other orthopedic procedures ${ }^{4}$ & $43(53.75)$ & $17(21.25)$ & $5(6.25)$ & 15 (18.75) & 80 \\
\hline Total & $110(54.46)$ & $42(20.79)$ & $14(6.93)$ & $36(17.82)$ & $202(100)$ \\
\hline
\end{tabular}

${ }^{1}$ Open Reduction and Internal Fixation

2 Total knee arthroplasty

${ }^{3}$ Total hip arthroplasty

${ }^{4}$ Such as Closed Reduction and Internal Fixation, amputation, correction of deformity, and ilizarov 
burden on patients. It is Important to recognize the risk of being infected among patients using risk assessment and to follow HAI prevention protocols in surveillance system. In this study, a statistically significant association was found between the type of microorganisms with the occurrence of SSIs in post- discharge or pre-discharge time. In addition, the average time interval between surgery to the incidence of infection has been significantly longer among post-discharge SSIs; this could occur due to different incubation and infectious periods among a variety of microorganisms and the effect on the appearance of infection symptoms after surgery [22]. However, the length of time between infection occurrence and its detection may be delayed because of the immune system response, consumption of prophylaxis, and being unaware of the infection symptoms.

After study on post- discharge and pre-discharge SSIs, it was observed that $76.24 \%$ of SSIs occurred after discharge, among which $45.54 \%$ occurred within 31 days after orthopedic procedure and, totally, $17.82 \%$ of SSIs were detected within 90 days to one year after orthopedic surgery. This varies by the type of orthopedic procedures. So that, $19.57 \%$ of SSIs due to ORIF procedures occurred post-discharge within 90 days to one year after surgery. These results were in line with other studies in which it was reported that the length of time between discharges to the detection of orthopedic SSIs varied between 8 days to 8 months. In another study, it was reported that most SSIs were detected after the 21st postoperative day $[23,24]$. As a result, this fact shows the importance of post-discharge surveillance, especially in procedures in which mechanical or prosthetic materials are implanted during surgery. Therefore, SSIs can occur in a late phase and post-discharge. So, performing a post-discharge surveillance can help the timely detection of SSIs and can prevent missing cases and under-estimation in registries systems.

As it was mentioned, In Iran, there are two independent registries in each hospital. One of them is HIM that generally recognizes and registers all disease cases using ICD-10 and ICD-9 criteria from medical reports of each patient. The other is NNIS that registers HAIs in each hospital. After collecting all reported HAIs from hospitals in the country, based on the NNIS report, all of them are reported to Iranian Center for Communicable Disease Control (ICCDC) in the Ministry of Health and Medical Education [25]. Thus, the number of HAIs and the incidence rate in country are based on case finding and case reporting of NNIS to upstream centers. After evaluation of the mentioned registry performance among six educational hospitals from March, 2017 to March, 2018, it was found that among 402 SSIs, just 241 records were reported from NNIS with $59.96 \%$ of total coverage (ranges from 50 to 90\%). About 161 orthopedic SSIs that were registered based on medical reports of patients were missed by NNIS. As a result, it can be said that the performance of NNIS among the mentioned hospitals was weak and about half of cases were not detected by NNIS. So, reported incidence rates are underestimated. According to a study done by Seifi, et al., which was conducted in a hospital in Iran, sensitivity, specificity, and positive and negative predictive values of routine surveillance were $27.5,97.2,69$, and $85.3 \%$, respectively [26]. Thus, we can say the performance of the routine surveillance system is poor. To have an effective case finding and increasing the data coverage, some changes are required to be made to the infrastructure and case finding protocols.

Furthermore, after capture-recapture was observed, the completeness of NNIS was $38.68 \%$. In other words, under-reporting of orthopedic SSIs among six educational hospitals was about $63.32 \%$. This finding was in line with another study in which underreporting of SSIs in ICU was 82.2\% in 2019 [26]. Under-reporting of SSIs in registry system is unavoidable; however, this issue can be overcome by recognizing the existing problems in the system. The possible problems in the NNIS system causing underreporting are as follows:

1 Lack of data linkage between emergency units of hospitals and private clinics with NNIS:

In Iran, only in-patients with severe HAIs, are registered as infected cases. Therefore, probable HAIS that are referred to private clinics or hospital emergency rooms are not being recorded as nosocomial infections and it leads to possibly of missing patients with subclinical infections;

2 Lack of data linkage between HIM unit and NNIS;

3 Lack of active surveillance system: NNIS in Iran is currently a passive surveillance, it means that health care workers report notifiable nosocomial cases on a case-by-case basis and it is impossible to ensure compliance by health care providers. so, it leads to under-reporting [27, 28];

4 Lack of post-discharge surveillance;

5 Non-reliable laboratory investigation methods (false-negative results): prescription of antibiotics, as a routine implementation before surgeries, can affect the results of laboratory tests [29] and can lead to false-negative and under-reporting;

6 Limited human and technical resources to register and quality control of NNIS.

With regard to the existing problems, it is recommended to plan for updating the existing prevention and controlling NNIS protocols in Iran. Some actions that can 
be taken are antibiotic prescription monitoring, assigning and retraining health care workers with experience of registry management and infection prevention and control, planning to provide the infrastructure for linkage of data among hospitals, clinics, and emergency units using electronic medical records, taking advantage of Standardized Infection Ratio (SIR) as a summary measure recommended by the National Healthcare Safety Network (NHSN) to track Health care-associated Infections (HAIs) [30], assigning a post-discharge surveillance according to the CDC 's recommendation based on monitoring the patients within 30 days of a surgical procedure or up to 90 days for implanted prosthetics [31]. Although this issue is difficult and challenging to implement, using active surveillance can be implemented and accessible. For example, using telephone interview as a diagnostic tool for postdischarge surveillance and follow-up of patients, have shown good results in terms of reliability and validity (72\% sensitivity and $100 \%$ specificity), [32] using questionnaires reported by physicians or surgeons and health care workers in local health centers [33], and providing advice to patients at the time of discharge to return for postoperative visits [34] can help to prevent and decrease the missed HAIs.

Some limitations of the current study should be noted. First, because of the lack of time and the large number of hospitals, we could not conduct a study on all educational hospitals in Tehran province. Second, since private hospitals did not cooperate, we conducted this study in six educational hospitals in Tehran.

\section{Conclusion}

In order for knowing the trends of mortality and morbidity in hospitals and in country also for aiding health care services for planning prevention strategy, it is important to have access to a registry with minimum underestimated data. Hence, according to the moderate coverage of NNIS and HIM data sources among Iranian hospitals, it is highly necessary to promote the national Infection Prevention and Control (IPC) programs and to provide updated protocols.

\footnotetext{
Abbreviations

ECDC: European Center for Disease prevention and Control; HAls: Health care-associated infections; HIM: Health Information Management;

IPC: Infection Prevention and Control; IQR: Interquartile Range; ICCDC: Iranian Center for Communicable Disease Control; LOS: Length of stay;

NIs: Nosocomial Infections; NNIS: National Nosocomial Infection Surveillance System; NHSN: National Healthcare Safety Network; ORIF: Open Reduction and Internal Fixation; SSIs: Surgical Site Infections; SIR: Standardized Infection Ratio; THA: Total Hip Arthroplasty; TKA: Total Knee Arthroplasty; WHO: World Health Organization
}

\section{Acknowledgments}

The authors would like to thank the research development office of six educational hospitals in Tehran province, and also Iranian Center for Communicable Disease Control (ICCDC) in the Ministry of Health and
Medical Education which participated in this project and provided us with their services.

\section{Authors' contributions}

NT collected data, analyzed and wrote the manuscript. YM advised on analysis and edited manuscript. AS and BE, reviewed the study. SSHN was study supervisor, designed the study and edited manuscript. All authors read and approved the final manuscript.

\section{Funding}

The study was supported by school of Public Health and Safety, Shahid Beheshti University of Medical Sciences (SBMU) under grant number 20554.

\section{Availability of data and materials}

An aggregated version of the data might be made available from the corresponding author on reasonable request with permission from the ethics committee.

\section{Ethics approval and consent to participate}

This article is adapted from a master's thesis in Epidemiology. The ethical approval was granted from the ethics committee and review board of the school of Public Health and Neuroscience Research Center (PHNS), Shahid Beheshti University of Medical Sciences (SBMU), Tehran, Iran (IR.SBMU.PHNS.REC.1398.101). Permission to access the raw data was granted by the Iranian Center for Communicable Disease Control (ICCDC) in the Ministry of Health and Medical Education and six hospitals affiliated to Tehran, Iran and Shahid- Beheshti university of medical sciences. The data of all cases was anonymized and was extracted with removal of identifiable information. The requirement for informed consent from participants was waived because of the registry-based nature of the study.

Consent for publication

Not applicable.

\section{Competing interests}

The authors declare that they have no competing interests.

\section{Author details}

${ }^{1}$ Department of Epidemiology, School of Public Health and Safety, Shahid Beheshti University of Medical Sciences, Tehran, Iran. ${ }^{2}$ Department of Infectious Diseases, Faculty of Medicine, Tehran University of Medical Sciences, Tehran, Iran. ${ }^{3}$ Center for Preventive Medicine, Department of Social Medicine, Iran University of Medical Sciences, Tehran, Iran. ${ }^{4}$ Prevention of Cardiovascular Disease Research Center, Department of Epidemiology, School of Public Health and Safety, Shahid Beheshti University of Medical Sciences, Tehran, Iran. ${ }^{5}$ School of Public Health and Safety, Shahid Beheshti University of Medical Sciences, Daneshjoo Blvd, Evin Ave, Tehran Postal code: 198353-5511, Iran

Received: 25 June 2020 Accepted: 7 December 2020 Published online: 04 January 2021

\section{References}

1. Fan $Y$, Wei $Z$, Wang $W$, Tan $L$, Jiang $H$, Tian $L$, et al. The incidence and distribution of surgical site infection in mainland China: a meta-analysis of 84 prospective observational studies. Sci Rep 2014;4:6783. PubMed PMID: 25356832. Pubmed Central PMCID: PMC4214160. Epub 2014/10/31. eng.

2. Horan TC, Gaynes RP, Martone WJ, Jarvis WR, Emori TG. CDC definitions of nosocomial surgical site infections, 1992: a modification of CDC definitions of surgical wound infections. Infect Control Hosp Epidemiol 1992;13(10): 606-608. PubMed PMID: 1334988. Epub 1992/10/01. eng.

3. Mardanpour K, Rahbar M, Mardanpour S, Mardanpour N. Surgical site infections in orthopedic surgery: incidence and risk factors at an Iranian teaching hospital. Clin Trials Orthop Dis. 2017;2(4):132-7.

4. Ghashghaee A, Behzadifar M, Azari S, Farhadi Z, Luigi Bragazzi N, Behzadifar $M$, et al. Prevalence of nosocomial infections in Iran: A systematic review and meta-analysis. Med J Islam Repub Iran. 2018;32: 48-. PubMed PMID: 30159299. eng.

5. Global Guidelines for the Prevention of Surgical Site Infection. Geneva: World Health Organization; 2018. 3, Important Issues in the Approach to 
Surgical Site Infection Prevention. Available from: https://www.ncbi.nlm.nih. gov/books/NBK536426/.

6. Purba AKR, Setiawan D, Bathoorn E, Postma MJ, Dik JH, Friedrich AW. Prevention of Surgical Site Infections: A Systematic Review of Cost Analyses in the Use of Prophylactic Antibiotics. Front Pharmacol. 2018;9:776. Published 2018 Jul 18. doi:https://doi.org/10.3389/fphar.2018.00776.

7. Healthcare-associated infections: surgical site infections - Annual Epidemiological Report for 2016. Available at: https://ecdc.europa.eu/en/ publications-data/healthcare-associated-infections-surgical-site-infectionsannual-0 Accessed Aug ,2019.

8. Health care-associated infections fact sheet. Available at: https://www. who.int/gpsc/country_work/gpsc_ccisc_fact_sheet_en.pdf Accessed Aug ,2019.

9. Maleknejad A, Dastyar N, Badakhsh M, Balouchi A, Rafiemanesh H, Al Rawajfah $\mathrm{O}$, et al. Surgical site infections in eastern Mediterranean region: a systematic review and meta-analysis. Infect Dis. 2019:1-11.

10. Mohebbi Z, Setoodeh G, Bagheri SH. Surgical site infection in the world and in Iran: Causes and outcomes. 2018. Available at: URL: https://www. omicsonline.org/proceedings/surgical-site-infection-in-the-world-and-in-irancauses-and-outcomes-93074.html. Accessed Jan, 2020.

11. Vieira Gde D, Mendonca HR, Alves Tda C, Araujo DF, Silveira Filho ML, Freitas AP, et al. Survey of infection in orthopedic postoperative and their causative agents: a prospective study. Rev Assoc Med Bras (1992). 2015; 61(4):341-346. PubMed PMID: 26466216. Epub 2015/10/16. eng.

12. Medical information unit in Iran.2019. Available at: http://treatment.sbmu.ac. ir/index.jsp?pageid=44918\&p=1 Access, Dec 2019 [in Persian].

13. Afhami S, Hadadi A, Khorami E, Seifi A, Esmailpour BN. Ventilator-associated pneumonia in a teaching hospital in Tehran and use of the Iranian Nosocomial Infections Surveillance software. EMHJ. 2013;19(10):883-7. https://apps.who.int/iris/handle/10665/118581.

14. Poorolajal J, Mohammadi Y, Farzinara F. Using the capture-recapture method to estimate the human immunodeficiency virus-positive population. Epidemiol Health. 2017; 39:e2017042. Published 2017 Oct 10. doi:https://doi.org/10.4178/epih.e2017042.

15. Chapman DG. The estimation of biological populations. Ann Math Stat. 1954:1-15.

16. Seber GAF. The effects of trap response on tag recapture estimates. Biometrics. 1970:13-22

17. Najjar YW, AI-Wahsh ZM, Hamdan M, Saleh MY. Risk factors of orthopedic surgical site infection in Jordan: A prospective cohort study. Int J Surg Open. 2018;15:1-6

18. Al-Mulhim FA, Baragbah MA, Sadat-Ali M, Alomran AS, Azam MQ Prevalence of surgical site infection in orthopedic surgery: a 5-year analysis. Int Surg. 2014;99(3):264-8. https://doi.org/10.9738/INTSURG-D-13-00251.1.

19. Haque M, Sartelli M, McKimm J, Abu Bakar M. Health care-associated infections - an overview. Infect Drug Resist. 2018; 11: 2321-2333. Published 2018 Nov 15. doi:https://doi.org/10.2147/IDR.S177247.

20. Nair A, Steinberg WJ, Habib T, Saeed H, Raubenheimer JE. Prevalence of healthcare-associated infection at a tertiary hospital in the northern Cape Province, South Africa. S Afr Fam Pract. 2018;60(5):162-7. https://doi.org/10. 1080/20786190.2018.1487211

21. Ducel G, Fubry J, Nicolle L. Prevention of hospital-acquired infections. Switzerland: WHO;2002-2012.p1,3.

22. Veloo AC, Elgersma PE, Friedrich AW, Nagy E, van Winkelhoff AJ. The influence of incubation time, sample preparation and exposure to oxygen on the quality of the MALDI-TOF MS spectrum of anaerobic bacteria. Clin Microbiol Infect. 2014;20(12):01091-7. https://doi.org/10.1111/1469-0691.12644.

23. Huenger F, Schmachtenberg A, Haefner H, Zolldann D, Nowicki K, Wirtz $D C$, et al. Evaluation of postdischarge surveillance of surgical site infections after total hip and knee arthroplasty. Am J Infect Control. 2005;33(8):455-62

24. Ercole FF, Franco LMC, Macieira TGR, Wenceslau LCC, Resende HINd, Chianca TCM. Risk of surgical site infection in patients undergoing orthopedic surgery. Rev Latino-Am Enfermagem 2011;19:1362-1368.

25. National Guideline of Nosocomial Infection Surveillance . 2020. Available at: https://www.who.int/patientsafety/events/media/iran_infection_surv. pdf?ua=1 Access Apr, 2020. [In Persian].

26. Seifi A, Dehghan-Nayeri N, Rostamnia L, Varaei S, Akbari Sari A, Haghani H, et al. Health care-associated infection surveillance system in Iran: reporting and accuracy. Am J Infect Control 2019:47(8):951-955. PubMed PMID: 3073 8720. Epub 2019/02/11. eng.
27. Eybpoosh S, Eshrati B. Nosocomial Infection Surveillance System in Iran: Structures, Processes and Achievements. Irje. 2019; 15 (1):105-115.URL: http://irje.tums.ac.ir/article-1-6287-fa.html [ln Persian].

28. National Passive Surveillance. 2020. Available at: https://www.who.int/ immunization/monitoring_surveillance/burden/vpd/surveillance_type/ passive/en/ Access Apr,2020.

29. Askarian M, Mahmoudi H, Assadian O. Incidence of nosocomial infections in a big University affiliated Hospital in Shiraz, Iran: a six-month experience. Int J Prev Med. 2013;4(3):366-72.

30. Surveillance for Surgical Site Infection (SSI) Events. 2020. Available at: https:// www.cdc.gov/nhsn/acute-care-hospital/ssi/index.html Access Apr,2020.

31. Borchardt RA, Tzizik D. Update on surgical site infections: the new CDC guidelines. JAAPA 2018;31(4):52-54. PubMed PMID: 30973535. Epub 2019/ 04/12. eng.

32. Platt $R$, Yokoe DS, Sands KE. Automated methods for surveillance of surgical site infections. Emerg Infect Dis. 2001;7(2):212-6. https://doi.org/10.3201/ eid0702.700212

33. Nguhuni B, De Nardo P, Gentilotti E, Chaula Z, Damian C, Mencarini P, et al. Reliability and validity of using telephone calls for post-discharge surveillance of surgical site infection following caesarean section at a tertiary hospital in Tanzania. Antimicrob Resist Infect Control. 2017;6(1):43.

34. Protocol for surgical site infection surveillance with a focus on settings with limited resources. 2018. Available at:https://www.who.int/infectionprevention/tools/surgical/SSI-surveillance-protocol.pdf Access Apr,2020.

\section{Publisher's Note}

Springer Nature remains neutral with regard to jurisdictional claims in published maps and institutional affiliations.

Ready to submit your research? Choose BMC and benefit from:

- fast, convenient online submission

- thorough peer review by experienced researchers in your field

- rapid publication on acceptance

- support for research data, including large and complex data types

- gold Open Access which fosters wider collaboration and increased citations

- maximum visibility for your research: over $100 \mathrm{M}$ website views per year

At BMC, research is always in progress.

Learn more biomedcentral.com/submissions 